\title{
Patients' Expectations in a Geriatric Rehabilitation Ward: Matching with Actual Outcomes
}

\author{
Mauro Colombo',2, Carla Facchini' ${ }^{3}$, Achim Rusu ${ }^{3}$, Eleonora Marelli1, Giuseppe Procino1, \\ Rosella Capuano ${ }^{1}$, Cristina Miramonti ${ }^{1}$, Antonio Guaita ${ }^{2}$ \\ ${ }^{1}$ Geriatric Rehabilitation Unit/Intermediate Care, Geriatric Institute "Camillo Golgi”, Agency for Services to Persons (ASP) Golgi \\ Redaelli, Milano, Italy \\ ${ }^{2}$ Golgi Cenci Foundation, Abbiategrasso, Italy \\ ${ }^{3}$ Sociology Department, University of Milan, Milano, Italy \\ Email:m.colombo@golgiredaelli.it, carla.facchini@unimi.it, a.rusu@campus.unimib.it, e.marelli@golgiredaelli.it, \\ g.procino@golgiredaelli.it, c.miramonti@golgiredaelli.it, r.capuano@golgiredaelli.it, a.guaita@golgicenci.it
}

How to cite this paper: Colombo, M., Facchini, C., Rusu, A., Marelli, E., Procino, G., Capuano, R., Miramonti, C. and Guaita, A. (2017) Patients' Expectations in a Geriatric Rehabilitation Ward: Matching with Actual Outcomes. Health, 9, 1597-1604. https://doi.org/10.4236/health.2017.911117

Received: July 31, 2017

Accepted: October 28, 2017

Published: October 31, 2017

Copyright (c) 2017 by authors and Scientific Research Publishing Inc. This work is licensed under the Creative Commons Attribution International License (CC BY 4.0).

http://creativecommons.org/licenses/by/4.0/

\section{c) (i) Open Access}

\begin{abstract}
Aim: Person-centered care is a core issue in rehabilitation; the study aims at: 1) enquiring the outcome expectations of patients in a geriatric rehabilitation ward; 2) matching outcome expectations with actual outcomes. Methods: Expectations of 186 patients [79.4 (8.7) years, 70\% females] analyzed through a questionnaire. $80.6 \%$ of patients were discharged home; functional recovery = 17.7 (22) points in Barthel Index total score, and 5 (4.2) points in Barthel Index walking sub-score; also conditions with nursing needs improved significantly. Results: Patients' expectations were coded as: functional (31.4\%), overall (29.6\%), and clinical improvement (21.5\%), discharge home (7\%); no answers or explicit lack of expectations (7.5\%). Walking ability recovery differed according to outcome expectations. Highest improvements were achieved by patients wishing clinical improvement, followed by those expecting functional or overall improvement (5 points) $[\mathrm{p}=0.009$ (Welch) $/ \mathrm{p}=0.041$ (BrownForsythe)]; worst improvement in walking ability ( 2.8 points) were got by patients faulting or declaring explicit failure of expectations. Conditions with nursing needs improved most in those expecting clinical improvements [ $\mathrm{p}=$ 0.029 (Brown-Forsythe)], and less in case of expectation default. No further matching was found. Conclusions: Improvement in actual outcomes matched expected improvements in two circumstances: recovery in walking ability and in conditions with nursing needs. The high yield of different favorable outcomes may have masked the statistical significance for correspondence between actual and expected results. Special attention is worthy towards patients
\end{abstract}


short of expectations, as their actual outcomes result poorer.

\section{Keywords}

Expectations, Outcomes, Geriatric Rehabilitation, Person-Centered Care

\section{Introduction}

Many older adults do not return to their premorbid health states following hospital admissions requiring a period of subacute inpatient rehabilitation. Yet, the efficacy of inpatient rehabilitation specifically designed for geriatric patients is supported by the literature [1] [2]. Valid results can be achieved notwithstanding the necessity to overcome adverse or unexpected clinical events, and to manage conditions like frailty and comorbidity [1] [2] [3] [4] [5]. Frail older patients face complex, multidimensional problems that specialized geriatric services have to address, in a comprehensive, multidisciplinary approach.

Outcome selection in patient care includes many goals, not all of which will be relevant for all patients [6]. Hence it may be beneficial for patients to have an accurate understanding of their likely recovery in order to make informed decisions about shared therapy goals and when planning for living in the community after discharge from a rehabilitative setting. Accurate understanding of likely therapeutic benefit and the personal capacity for improvement is constructive for informing joint decision making between patients and health professionals and to facilitate adherence to therapeutic protocols. Such vision stands at the core of person-centered models of care that are becoming increasingly common among subacute rehabilitation facilities. Such models of care may assist older patients recovering from illness or injury to work with their treating team to focus therapy and other treatments on deficits that are most important for them, in order to optimize their health-related quality of life at discharge or thereafter [7].

Yet, literature on matching between patients' expectations and their rehabilitative outcomes is scanty.

\section{Paper's Purpose}

The aim of our study was twofold: 1) to investigate clients' expectations about outcomes from staying in our geriatric rehabilitation ward, and 2) to check the matching between such expectation and actual outcomes.

\section{Material and Methods}

The study is designed as retrospective evaluation of rehabilitative outcome of elderly patients, matched to their respective expectations.

\subsection{Context}

Survey on ordinary activity within a rehabilitative/intermediate care ward. Due 
to the exploratory and retrospective nature of our enquiry, neither sample size calculation nor selection (inclusion/exclusion) criteria were applied. Data pertain to patients consecutively admitted to the ward since September 2012 to march 2014.

Data used for analysis were collected as part of routine clinical practice: therefore formal approval by the local ethics committee was not sought.

\subsection{Outcome and Explanatory Measures}

Expectations were drawn from an open field within an on purpose, closed questions questionnaire, delivered to clients at entry. The self-made questionnaire taps issues relevant to the stay [e.g.: relationships with staff, privacy, food]; it is delivered at entry and recollected after about one week, in order to give patients time to get acclimatized to the ward. Free lines are available in the format to answer the explicit question: "What do You expect from your rehabilitative stay?".

Expectations answers were coded in a two step process: the first step yielded 9 main categories, that were subsequently brought into 5 broad categories: functional improvement, clinical improvement, overall improvement, discharge to home, no expectation [either implicitly or explicitly].

Functional, clinical and outcome information were registered through a standardized data collection form. Such data collection system has been previously validated elsewhere [3]. After general and demographic variables, it comprehends typical measures of multidimensional assessment, including the pre-morbid modified Rankin Scale (mRS) [8], the Barthel Index (BI) [9], and the Mini-Mental State Examination (MMSE) [10] [11]. Besides the BI, also performances through POMA test by Tinetti et al. were measured both at entry and at discharge [12] [13]. A core set of dichotomous standardized indicators and validated assessment tools follows in the collection form. Specifically, the conditions with nursing needs -assessed at admission and at discharge in a dichotomous checklistwere: dysphagia, malnutrition, nasogastric tube or percutaneus endoscopic gastrostomy, pressure sore, indwelling bladder catheter, urinary incontinence, central venous catheter and tracheostomy [3].

\subsection{Sample}

Sociodemographic, functional and clinical characteristics of the participants are summarized in Table 1. Briefly, 186 patients consecutively were admitted to the ward since fall 2012 to spring 2014: some adult people are included in a sample predominantly constituted by elderly persons. Primary reasons for admission spanned through a wide range of diseases: muscolar-skeketal disorders [either fractures-mostly femur fractures (18\%) - or degenerative diseases, including elective arthroplasty (21\% overall)], neurologic impairments [stroke (11\%), Parkinson's disease and parkinsonism (3\%), neuropathies (5\%)], deconditioning syndromes due to various medical and/or surgical conditions (25\%). Overall, the 
Table 1. Sociodemographic, functional and clinical characteristics of the participants.

\begin{tabular}{cc}
\hline Feature & $\begin{array}{c}\text { Descriptive }[\% / \text { mean (s.d.)/median, } \\
\text { mode and interquartile range }]\end{array}$ \\
\hline Sex (female) & $70 \%$ \\
Age & $79.4(8.7)$ \\
Pre-morbid modified Rankin Scale & $3,3,2-4$ \\
Pre-morbid Barthel Index total score & $85,100,70-97$ \\
MMSE classes at admission & $25-30=39 \%$ \\
Cardiac and/or respiratory and/or hepatic and/or & $18.4 \%$ \\
renal failure at admission & $10 \%$ \\
Pressure sores $\geq$ stage 2 EPUAP * at admission & $35 \%$ \\
Urinary incontinence at admission & Non-urinary $10 \%$; urinary $17 \%$ \\
Infections at admission &
\end{tabular}

*EPUAP: European Pressure Ulcer Advisory Panel classification [14].

sample was characterized - as an administrative admission requisite-by pre-morbid physical and or cognitive frailty or partial dependency, and/or co-morbidity, as shown by pre-morbid Barthel Index total score. At entry, 3 out of 5 patients showed poor cognitive performance, according to MMSE total score classes. Clinical conditions were often compromised at admission: beyond what reported into Table 1, $8 \%$ of patients active tumor; $7 \%$ had dysphagia, 13 hosted an\% indwelling urinary catheter; $15 \%$ were clinically instable according to Hulm criteria [3]; 9\% had moderate to severe dementia and 5\% delirium-assessed according to Confusion Assessment Method-[15]; 48\% were clinically depressed.

\subsection{Statistical Analysis}

Descriptive and inferential analysis are performed according to normal or not-normal data distributions; the SPSS software was employed.

\section{Results}

\subsection{Expectations}

Recoded expectations were distributed as follows: functional improvement $31.4 \%$, overall improvement $29.6 \%$, clinical improvement $21.5 \%$, home discharge 7\%; $7.5 \%$ of answers were blank or explicitly declared having no expectations.

No baseline characteristics differed according to expectations, except for MMSE values, which were lower for patients whose answers were blank or explicitly declared having no expectations [14.9/30 (s.d. 8,3/30) and higher for people aiming primarily to go back home $[25.1 / 30$ (s.d. 3.9/30)] $(\mathrm{p}=0.013)$.

Neither length of stay nor rehabilitative sessions numbers differed according to expectations. 


\subsection{Outcomes}

As shown in Table 2, the case mix at entry is featured by high levels of dependency in basic activities of daily life, with special regards to walking ability; further, patients at admission were usually charged by one condition with nursing needs. All these three variables significantly improved at discharge; overall dependency in basic activities of daily living shifted by one category according to total Barthel Index score. At discharge, most people were able to walk independently in short range (50 meters), with supervision and/or walking aid if needed [see median and modal value of locomotion item at Barthel Index]. Most people were discharged free of conditions requiring nursing needs.

\subsection{Expectations/Outcomes Matching}

In one case the match between expectations and actual outcomes was fulfilled. Improvements in conditions with nursing needs was highest in patients whose expectations were clinical improvement $[\mathrm{p}=0.029$ (Brown-Forsythe)]. Further, highest improvements in walking ability (6.2 points at specific Barthel Index item) were achieved by patients prioritizing a clinical improvement, followed by those aiming at functional as well as overall improvement (5 points at specific Barthel Index item) $[\mathrm{p}=0.009$ (Welch); $\mathrm{p}=0.041$ (Brown-Forsythe)]. In both cases, worst outcomes were got by patients without implicit or explicit expectations: smallest improvements in walking ability (2.8 points at specific Barthel Index item) or stability in conditions requiring nursing needs, respectively. No further statistically significant matching were found between expectations and outcomes. The number of rehabilitative sessions attended did not vary according to expectations.

\section{Discussion}

In previous works, we got valuable rehabilitative results, even in case of cognitive impairment, pursuing our geriatric paradigm [to "select" (true from irrelevant) and to "hierarchy" (top/bottom) problems, in order to link together interventions and solutions] [16]. Here we focused onto patient's expectations. At least in one matter, clients' expectations about rehabilitation outcomes were achieved: it is the case of clinical improvements, in terms of conditions with nursing needs. Otherwise, the overall good results-in terms of clinical, functional and

Table 2. Functional abilities (overall basic activities of daily living and walking) and conditions with nursing needs, at admission and at discharge.

\begin{tabular}{cccc}
\hline $\begin{array}{l}\text { Variables in row } \\
\text { Median (mode) }\end{array}$ & $\begin{array}{c}\text { Barthel total } \\
\text { score }\end{array}$ & $\begin{array}{c}\text { Barthel walking } \\
\text { ability }\end{array}$ & $\begin{array}{c}\text { conditions with } \\
\text { nursing needs }\end{array}$ \\
\hline Admission & $53(43)$ & $3(8)$ & $1(1)$ \\
Discharge & $79(99)$ & $12(12)$ & $0(0)$ \\
Significance $(\mathrm{p})$ & $<0.001$ (Wilcoxon) & $<0.001$ (Wilcoxon) & $<0.001$ (Wilcoxon) \\
\hline
\end{tabular}


social outcomes-overcame and covered other matching between expectations and outcomes. The topic of the association between improvements in walking ability with expectations not only in functional improvement, but also with clinical and overall improvement, is emblematic.

Our study has some limitations, including the focus in a unique sample, that hampers generalizability. More, McPhail and Haines warned about the risk of a self-fulfilling prophecy in case patients feeling helpless and anticipating poor levels of physical functioning, pain and depression might be less likely to participate in therapies and other treatments. Vice versa, patients exhibiting a positive outlook and high levels of self-efficacy might maximize their rehabilitation outcome through active participation during their rehabilitation stay [17]. A further weakness of our study is the lack of information about the quality of patients' participation to the rehabilitative sessions. Yet, finding no quantitative differences in the attendance to rehab sessions might mitigate the risk of such self-fulfilling prophecy. The study has also some strengths. It is in line with some previous experience. In an Australian study, old patients admitted for subacute in-hospital rehabilitation were able to anticipate their discharge health-related quality of life with a moderate level of accuracy. Such ability held also for patients with poorer cognition [17]. Patients' views might be mirrored by professionals' ones, according to some literature hints. Physiotherapists in the same Australian subacute rehabilitation setting predicted their patients' discharge health-related quality of life with substantial accuracy [7]. The prediction accuracy was higher among patients with better cognition than patients with poorer cognition.

Expectations declared by our patients are similar to those disclosed in a rehabilitative sample studied in the frame of goal attainment [6].

Previously, we shown elsewhere that customer satisfaction was realistically related to reasonably attainable functional as well as clinical outcomes, in the same rehabilitative setting [18]. Further, we found that trends in self-perceived health paralleled improvements in objective functional gauges and subjective indicators, as expected [19]. Yet our correlations were weak, according to the literature [20].

Poor outcomes of patients short of expectations raise concern. In wealthy persons, positive expectations regarding aging were associated with better physical function while getting old, as well as with increased longevity. Vice versa, those with more negative expectations were less likely to report engaging in physical activity [21]. The issue of keeping the locus of control maintains its basic importance for elderly individuals with somatic health problems [22] [23].

\section{Conclusion}

In a geriatric rehabilitative setting, most dependent, comorbid, frail elderly patients stated a set of reasonable expectations about their outcomes. Improvement in actual outcomes matched expected improvements in two circumstances: re- 
covery in walking ability and in conditions with nursing needs. The high yield of different favorable outcomes may have masked the statistical significance for correspondence between actual and expected results. Special attention must be paid towards patients short of expectations, as their actual outcomes result poorer.

\section{Acknowledgements}

We are grateful to the whole staff of the ward for the commitment to patients' expectations and outcomes, and to ASP administration for the support in our effort.

\section{References}

[1] Bachmann, S., Finger, C., Huss, A., Egger, M., Stuck, A.E. and Clough-Gorr, K.M. (2010) Inpatient Rehabilitation Specifically Designed for Geriatric Patients: Systematic Review and Meta-Analysis of Randomised Controlled Trials. BMJ, 340, c1718. https://doi.org/10.1136/bmj.c1718

[2] Bellelli, G., Guerini, F., Bianchetti, A., De Palma, D., Ther, P. and Trabucchi, M. (2002) Medical Comorbity and Complexity of the Rehabilitative Procedures for Older Patients with Functional Impairments. Journal of the American Geriatrics Society, 50, 2095-2096. https://doi.org/10.1046/j.1532-5415.2002.50628.x

[3] Bellelli, G., Bernardini, B., Pievani, M., Frisoni, G.B., Guaita, A. and Trabucchi, M. (2012) A Score to Predict the Development of Adverse Clinical Events after Transition from Acute Hospital Wards to Post-Acute Care Settings. Rejuvenation Research, 15, 553-563. https://doi.org/10.1089/rej.2012.1332

[4] Gurwitz, J.H., Sanchez-Cross, M.T., Eckler, M.A. and Matulis, J. (1994) The Epidemiology of Adverse and Unexpected Events in the Long-Term Care Setting. Journal of the American Geriatrics Society, 42, 33-38. https://doi.org/10.1111/j.1532-5415.1994.tb06070.x

[5] Yancic, R., Ershler, W., Satariano, W., Hazzard, W., Cohen, H.J. and Ferrucci, L. (2007) Report of the National Institute on Aging Task Force on Comorbidity. Journal of Gerontology Medical Sciences, 62A, 275-280. https://doi.org/10.1093/gerona/62.3.275

[6] Stolee, P., Stadnyk, K., Myers, A.M. and Rockwood, K. (1999) An Individualized Approach to Outcome Measurement in Geriatric Rehabilitation. Journal of Gerontology Medical Sciences, 54A, M641-M647. https://doi.org/10.1093/gerona/54.12.M641

[7] McPhail, S.M., Nalder, E., Hill, A-M. and Haines, T.P. (2013) Physiotherapists Have Accurate Expectations of Their Patients' Future Health-Related Quality of Life after First Assessment in a Subacute Rehabilitation Setting. BioMed Research International, Article ID 340371.

[8] Quinn, T.J., Dawson, J., Walters, M.R. and Lees, K.R. (2009) Reliability of the Modified Rankin Scale. Stroke, 40, 3393-3395. https://doi.org/10.1161/STROKEAHA.109.557256

[9] Shah, S., Vanclay, F. and Cooper, B. (1989) Improving the Sensitivity of the Barthel Index for Stroke Rehabilitation. Journal of Clinical Epidemiology, 42, 703-709. https://doi.org/10.1016/0895-4356(89)90065-6

[10] Folstein, M.F., Folstein, S.E. and McHugh, P.R. (1975) Mini-Mental State: A Prac- 
tical Method for Grading the Cognitive State of Patients for the Clinician. Journal of Psychiatric Research, 12, 189-198. https://doi.org/10.1016/0022-3956(75)90026-6

[11] Tombaugh, T.N. and McIntyre, N.J. (1992) The Mini-Mental State Examination: A Comprehensive Review. Journal of the American Geriatrics Society, 40, 922-935. https://doi.org/10.1111/j.1532-5415.1992.tb01992.x

[12] Tinetti, M.E. (1986) Performance-Oriented Assessment of Mobility Problems in Elderly Patients. Journal of the American Geriatrics Society, 34, 119-126. https://doi.org/10.1111/j.1532-5415.1986.tb05480.x

[13] Cipriani-Dacko, L.M., Innerst, D., Johannsen, J. and Rude, V. (1997) Interater Reliability of the Tinetti Balance Score in Novice and Experienced Physical Therapy Clinicians. Archives of Physical Medicine and Rehabilitation, 78, 1160-1164.

[14] European Pressure Ulcer Advisory Panel (1999) Guidelines on Treatment of Pressure Ulcers. EPUAP Review, 1, 31-33.

[15] Inouye, S.K., van Dyck, C.H., Alessi, C.A., Balkin, S., Siegal, A.P. and Horwitz, R.I. (1990) Clarifying Confusion: The Confusion Assessment Method. A New Model for Detection of Delirium. Annals of Internal Medicine, 113, 941-948. https://doi.org/10.7326/0003-4819-113-12-941

[16] Colombo, M., Guaita, A., Cottino, M., Previderé, G., Ferrari, D. and Vitali, S. (2004) The Impact of Cognitive Impairment on the Rehabilitation Process in Geriatrics. Archives of Gerontology and Geriatrics Supplement, 9, 85-92.

[17] McPhail, S. and Haines, T. (2012) Patients Undergoing Subacute Rehabilitation Have Accurate Expectations of Their Health-Related Quality of Life at Discharge. Health and Quality of Life Outcomes, 10, 94. https://doi.org/10.1186/1477-7525-10-94

[18] Colombo, M., Guaita, A., Cottino, M., Cairati, M., Ferrari, D., Previderè, G., Procino, G., Gandolfi, C., Tararà, R. and Mercanti, A. (2009) Customer Satisfaction as a Quality Factor in Geriatric Rehabilitation. The Open Geriatric Medicine Journal, 2, 1-4. https://doi.org/10.2174/1874827900902010001

[19] Marelli, E., Procino, G., Cottino, M., Previderè, G., Giorgi, S., Dell'Acqua, D., Bruno, S., Cairati, M., Ferrari, D., Capuano, R. and Colombo, M. (2013) Modification in Self-Rated Health in Patients Discharged by a Geriatric Rehabilitation Ward. Health, 5, 94-98. https://doi.org/10.4236/health.2013.56A2014

[20] Edwards, S.G.M., Playford, E.D., Hobart, J.C. and Thompson, A.J. (2002) Comparison of Physician Outcome Measures and Patients' Perception of Benefits of Inpatient Neurorehabilitation. BMJ, 324, 1493. https://doi.org/10.1136/bmj.324.7352.1493

[21] Breda, A.I. and Watts, A.S. (2017) Expectations Regarding Aging, Physical Activity, and Physical Function in Older Adults. Gerontology \& Geriatric Medicine, 3, 1-8. https://doi.org/10.1177/2333721417702350

[22] Helvik, A.-S., Iversen, V.C., Steiring, R. and Hallberg, L.R. (2011) Calibrating and Adjusting Expectations in Life: A Grounded Theory on How Elderly Persons with Somatic Health Problems Maintain Control and Balance in Life and Optimize Well-Being. International Journal of Qualitative Studies on Health and Well-Being, 6, 6030. https://doi.org/10.3402/qhw.v6i1.6030

[23] Reddy, P., Martinez-Martin, P., Brown, R.G., Chaudhuri, K.R., Lin, J.-P., Selway, R., Forgacs, I., Ashkan, K. and Samuel, M. (2014) Perceptions of Symptoms and Expectations of Advanced Therapy for Pakinson's Disease: Preliminary Report of a Patient-Reported Outcome Tool for Advanced Parkinson's Disease (PRO-APD). Health and Quality of Life Outcomes, 12, 11. http://www.hqlo.com/content/12/1/11 https://doi.org/10.1186/1477-7525-12-11 